\title{
1950-2025: DE UN MODELO ECONÓMICO SUSTENTADO EN LA ABUNDANCIA A OTRO SUSTENTADO EN LA ESCASEZ
}

\author{
Autores: Santiago Niño Becerra ${ }^{1}$ \\ Catedrático de Estructura Económica \\ IQS School of Management \\ Universidad Ramon Llull
}

\section{Resumen}

Un sistema económico es un conjunto de normas filosóficas cuya implementación en un instante dado determina una estructura de funcionamiento que permanece vigente en un período histórico; su manifestación operativa en cada momento se produce a través del modelo económico. Al igual que el crash de 1929 supuso el fin, por agotamiento, del modelo vigente desde 1873, la crisis sistémica actual ha puesto de manifiesto el agotamiento del modelo iniciado tras la II Guerra Mundial. Años de crisis durante los que se está diseñando el modelo adecuado para las necesidades de los años venideros.

\footnotetext{
${ }^{1}$ santiago.nino@iqs.url.es
} 
Palabras clave: sistema económico; modelo económico; crisis sistémica.

\title{
1950 - 2025, the transition from an economical model based on abundance to one based on scarcity
}

\begin{abstract}
Every economical system is a combination of philosophical norms that, implemented in a precise historical moment, bring about a functional structure that remains in force all along a specific period; its operative manifestation at every moment of time is the result of a specific economical model. If the crash of 1929 meant the end, by exhaustion, of the model that began in 1873, the present day systemic crisis has shown the exhaustion of the model that began after World War II. These are crisis years in which a new model is being created with a view to become adequate for the needs of coming years.
\end{abstract}

Key words: economical system; economical Model; systemic crisis.

Recibido: 23-03-2015

Aceptado: 01-09-2015

Si un concepto caracteriza a estos años que estamos viviendo es el de tránsito. Desde el año 2010 -con unos antecedentes que se remontan al 2007-, el planeta se halla inmerso en una crisis sistémica como resultado del agotamiento de "una forma de hacer": del modelo económico y social que el planeta ha estado utilizando, y que finalizará con la puesta en marcha de un nuevo modelo económico y social.

Una crisis sistémica no es una situación que se pueda superar variando los tipos de interés, imprimiendo más dinero, o comprando o vendiendo deuda pública; así se pone fin a una recesión que puede ser más o menos profunda. Una crisis sistémica es un cataclismo en el que un modelo que se ha estado utilizando durante décadas colapsa debido a que han llegado al agotamiento los motores que lo propulsaban. Recesiones fueron lo sucedido en 1962, en 1973, en 1987, en 1991 o en el 2000. Crisis sistémicas fueron lo acontecido en 1873, en 1929 y actualmente. Las primeras, pudiendo ser muy duras, son relativamente breves: dos, tres años; las segundas son prolongadas: diez años como mínimo. Las recesiones tienen causas variadas por lo que sus escenarios pueden ser muy diferentes; las crisis sistémicas al tener la misma causa son estructuralmente muy semejantes, variando la forma en que se manifiestan. 
La última crisis sistémica habida en el planeta se extendió entre 1929 y 1950. Fue una crisis que se produjo por el agotamiento del modelo que había estado vigente entre 1873 y 1930, y empezó como comienzan este tipo de crisis: con un crash, el de 1929. Una de las características comunes a las crisis sistémicas es que hay algún o algunos elementos económicos y/o sociales que quedan completamente trastocados y que jamás vuelven a una posición que remotamente se parece a la adoptaba con anterioridad a la crisis. En la crisis de 1930 fundamentalmente fueron dos.

Por un lado, el fin de la "Mano Invisible", aquel instrumento intangible e inmaterial que hacía que el mercado volviera a su natural situación de equilibrio cuando se producía algún tipo de distorsión que le apartaba de la estabilidad, una situación que se caracterizaba por el "Laissez faire, laissez passer". El modelo que sustituyó al que colapsó en el 29 introdujo la regulación financiera, instauró los instrumentos necesarios para lograr el pleno empleo de todos los factores productivos, y puso en marcha el modelo de protección social a fin cuidar de la población que producía, consumía y pagaba impuestos para que pudiera desempeñar sus tareas en un entorno de paz social. Por otro, se produjeron cambios radicales en el modelo de familia, pasándose de una estructura familiar compacta en la que dos o tres generaciones podían compartir vivienda a otra dispersa en la que cada uno de los miembros de familia podían estar desperdigados por un país o uno o varios continentes.

La crisis sistémica que actualmente se está viviendo, que ha escenificado el agotamiento del modelo vigente entre 1950 y el 2010, y que siguiendo los parámetros temporales que se dieron en la anterior crisis se extenderá hasta el 2020 / 2025, plantea un decorado muy disruptivo con el pasado:

- En España se ha estimado ${ }^{2}$ que para cuando finalice la crisis y suponiendo que en la economía española se lleven a cabo las actuaciones precisas, el desempleo estructural podría situarse en el 18\% de la población activa.

- Diversas interpretaciones han concluido que en Europa podría estar instalándose la llamada "enfermedad japonesa", una especie de estancamiento como el desatado en Japón tras la explosión de su burbuja inmobiliaria y financiara a principios de los 90, y que en gran medida continúa.

- El ya mencionado estancamiento de la economía japonesa que la enorme inyección monetaria puesta en marcha en el 2012 y destinada -oficialmente- a elevar la inflación no ha revertido y que, sin embargo, sí ha influido en una acelerar una larvada guerra de divisas que comenzó a fraguarse desde que con la crisis los diversos países han estado intentando canalizar a través de sus exportaciones los descensos en su consumo interno.

${ }^{2}$ BBVA Research, noviembre 2014.

icade. Revista cuatrimestral de las Facultades de Derecho y Ciencias Económicas y Empresariales, no 96 septiembre-diciembre 2015, ISSN: 1889-7045 


\section{Santiago Niño Becerra}

- Estados Unidos parece que está al margen de todos los desastres que afligen al resto del mundo, pero lo cierto es que la economía estadounidense lleva cinco años funcionando a base de inyecciones de dinero -anfetaminas-que la Reserva Federal lanza al mercado comprando prácticamente cualquier papel que le presentan por ventanilla y que ha elevado su pasivo hasta casi 4,5 billones de dólares; unos dólares que valen lo que Estados Unidos dicen que valen y por un valor que el resto del mundo acepta ... de momento.

- El año 2014 ha sido para China el año en que ha tenido el menor crecimiento de los últimos 24 años: el 7,4\%, es decir, el 0,9\%. La economía china precisa crecer al 6,5\% anual, como mínimo, tan sólo para absorber la nueva población activa que cada año se incorpora al mercado laboral. El propio Gobierno chino ha admitido que el modelo vigente desde 1979 basado en las exportaciones está agotado.

- Latinoamérica, Brasil muy especialmente, está dejando atrás aquellos años de boom sustentado en las exportaciones de commodities, en la entrada de capitales exteriores, en el endeudamiento interno, y volviendo a una posición conocida: bajos crecimientos y concentración de la renta. ¿El motivo? La crisis que ha reducido la demanda de sus materias primas, sobre todo por parte de China.

- En el planeta parece que se está instalando el denominado por Lawrence Summers "estancamiento secular" (Secular Stagnation), una situación de muy reducido crecimiento económico acompañado de una estabilidad de precios prácticamente absoluta. Junto a eso, añadido a eso, una deuda total monstruosa.

- Y todo lo anterior acompañado de unos consumos estimados de petróleo para el 2019 semejantes a los habidos en el 2013. Y con unas Bolsas carísimas y sin inversores finales que se van alimentando con los fondos proporcionados por el propio sistema.

- (Y en este espacio añadan lo que crean oportuno que seguro que algo encuentran para apuntar).

Un decorado muy disruptivo con el pasado en cuanto al "modo de hacer las cosas", en cuanto al modelo, pero no en cuanto al continente, al marco donde ese modelo tiene su razón de existencia: el sistema. Es decir, las características esenciales del sistema capitalista van a continuar inmutables, es más, con toda seguridad tenderán a agudizarse: en lo tocante al sistema productivo, la tendencia natural del capitalismo a adoptar posiciones monopolistas u oligopolistas se acrecentará al tenderse hacia la eficiencia a fin de conseguir significativas reducciones de costes; y en cuanto las rentas, debido a lo anterior y a la paulatina disminución del número de actores se producirá una lógica concentración. Volveremos sobre esto. 
De alguna forma puede llegarse ya a una primera conclusión. El modelo vigente hasta ahora: 1950 - 2010, fue un modelo que tendió a mitigar esas dos características del capitalismo. Unos sistemas fiscales muy progresivos y un gasto público suficiente sobre todo personalizado en el modelo de protección social, y junto a eso una legislación reguladora estricta -que fue suavizándose hasta prácticamente desaparecer a partir de la década de los 80- evitaron o redujeron en gran medida tanto la concentración de capacidades productivas como de rentas; evidentemente la atmósfera de Guerra Fría que envolvía el planeta ayudó: había que mantener la paz social en Occidente y evitar que la clase obrera atendiese a consignas que no debía. Pero ya no hay nada que mitigar porque han desaparecido las circunstancias que llevaron a tal necesidad, fundamentalmente la necesidad decreciente de factor trabajo.

Bien. Agotado el modelo por el agotamiento de la capacidad de utilización de factores productivos y de la capacidad de absorción de bienes y servicios producidos se entró en una crisis sistémica, crisis que hay que gestionar, y gestión que se concretiza en el tránsito del modelo anterior ya agotado al nuevo aún en formación, lo que significa sustituir la esencia del modelo agotado por otra nueva.

La esencia del modelo hasta hace poco vigente pude resumirse en "Ir-a-más". El crecimiento permanente, mayores producciones de todo alimentando a ofertas crecientes que eran exportadas o consumidas (la inversión no deja de ser consumo) en el interior y pagadas con salarios crecientes de una población activa plenamente ocupada - al principio- o por una deuda privada en aumento permanente. A resaltar que el consumo de todo, es decir, la absorción de la producción, era la clave que sostenía al modelo. Pero eso ya ha finalizado.

Por un lado porque esa capacidad ilimitada de absorción ha desaparecido, por otro porque vista desde fuera esa forma de hacer es ineficiente ya que implica el desperdicio o el deficiente uso de unos recursos que ahora se saben escasos. Esto lleva a otro lugar al que también volveremos: si esa forma de operar ha llevado a la crisis que se está viviendo al agotarse su dinámica, es imposible enderezar la situación -suponiendo que enderezarla fuese posible- utilizando los procederes usados hasta ahora.

El nuevo modelo, resumiendo también su esencia, debe "Ir-a-lo-conveniente". A aquello que sea preciso, necesario, eficiente; a aquello que evite el despilfarro, la subutilización, el mal uso: a aquello que logre el equilibrio.

Por ello la gestión de tránsito de un modelo a otro supone diseñar y favorecer el paso de las bases sustentadoras y de los elementos definitorios del modelo agotado a las bases que sustentarán y a los elementos que definirán el siguiente. En otras palabras, esta crisis es el tiempo con que se cuenta para definir, diseñar e implementar el nuevo modelo, del mismo modo que entre 1930 y 1950 se definió, diseñó e implementó el modelo que sustituyó al que entró en crisis en 1929. 


\section{Santiago Niño Becerra}

Tránsito: el paso de un modelo a otro. El cambio de señas operativas. La sustitución de los procederes que son propios a una forma de hacer por otros. Lo que es básico, fundamental, conceptualmente esencial en el que ha sido y lo que puede ser en el que será:

\begin{tabular}{lll}
\multicolumn{1}{c}{ Modelo antiguo } & & \multicolumn{2}{c}{ Nuevo modelo } \\
\cline { 1 - 1 } $\begin{array}{l}\text { Producción } \\
\text { Individuo }\end{array}$ & & Productividad \\
Individualismo & & Colaboración / Coordinación \\
Protección & & Responsabilidad \\
Centralización / Descentralización & & Descentralización - centralizada \\
Compra & & Uso \\
Propiedad & Acceso \\
Indefinido y Fijo & Temporal y Autónomo \\
Estado / Región & Cluster / Municipio \\
Políticos & Técnicos \\
Pluriunidades productivas verticales & Corporaciones horizontales \\
"Lo elegido" & "Lo conveniente" \\
The Great Society & The Big Society
\end{tabular}

Y esta gestión del tránsito deberá llevarse a cabo en un escenario de crisis múltiple:

- Crisis de deuda. La deuda total, pública y privada, ha alcanzado un nivel tal que nadie puede pagar todo lo que debe, lo que ocasiona una situación compleja al obligar al sostenimiento de una deuda impagable a fin de evitar una suspensión de pagos generalizada de consecuencias imprevisibles.

- Crisis de confianza. Se duda de todo, pero se mantiene la compostura a fin de no ocasionar tensiones. Se duda incluso de la efectividad de las medidas que se toman.

- Crisis de certidumbre. No se vislumbran soluciones definitivas a los problemas existentes, por lo que las políticas que se adoptan son más bien parches.

- Crisis de sobreproducción. Como consecuencia de los aumentos de capacidad productiva y de productividad habidos en los 90 y los 2000 han sido generados unos excedente inabsorbibles de capacidad productiva, fruto de lo cual existen cantidades elevadas de factores productivos no utilizados ni necesarios. 
- Crisis de subconsumo. La capacidad productiva generada lo fue para satisfacer una demanda elevadísima y creciente. Cuando se agotó el recorrido al alza de los salarios se incrementó, por parte del sector bancario, la capacidad de endeudamiento de familias y empresas hasta donde hizo falta y la cantidad que hizo falta; a la que físicamente se agotó la capacidad de endeudamiento, el consumo-de-todo empezó a caer poniendo de manifiesto lo indicado en el punto anterior.

- Crisis de empleo. El pleno empleo del factor trabajo existente en los 50, 60 y gran parte de los 70 se debió a la creciente demanda tanto pública como privada, y el altísimo nivel de ocupación de los 2000 a un crédito inagotable. Con particularidades, eso fue así en todos los países, pero cuando la crisis llegó las inmediatas reducciones de costes se emprendieron por el lado de las rescisiones de contratos de trabajo, a las que se unieron los cierres de empresas que no han soportado las consecuencias de la crisis. Existe un excedente de oferta de trabajo que está derivando en desempleo estructural y en subempleo involuntario, con los efectos que ello tiene en los ingresos de amplias capas de la sociedad.

- Crisis fiscal. Entre los años 50 y 70 un signo de progresividad social era el que la recaudación fiscal procedente de los impuestos directos fuese mayor que la de los indirectos, luego ese objetivo se abandonó para, se dijo fomentar la inversión y el consumo. Caídas en este y un subempleo creciente afectan directamente a los ingresos públicos: la situación financiera de la Seguridad Social española es un ejemplo, la lentitud en la reversión del déficit fiscal del Estado y de los entes autonómicos y locales, otro. El sistema no obtiene ingresos suficientes, luego la vía es la de los recortes de los gastos.

- Crisis tecnológica. A mediados del siglo XX "las cosas": las obras de arte, las inversiones financieras, los diseños,... tenían vocación de permanencia, con la crisis, ya antes -ese fue uno de sus avisos- todo quedaba envejecido en cuanto salía de las plantas de fabricación y llegaba a la calle. La obsolescencia, programada o no, era instantánea. En las áreas tecnológicas este proceso era evidente, pero no sólo se daba ahí. La moda, los bienes de consumo duradero y no duradero, todo envejecía a una velocidad imposible de seguir. El consumo desempeñó un papel fundamental en el proceso como motor del mismo y como alimentador de su motor.

- Crisis social. USA, con su modelo de protección social limitado y parcial, pero con oportunidades de empleo abundantes hasta los años 80 es un buen ejemplo de cómo han evolucionado las cosas a nivel social en el planeta. Tomando como inicio el valor en 1947 de la productividad, las compensaciones salariales y no salariales percibidas por el trabajo en una hora y el importe del salario horario, en 1979 la productividad había ascendido hasta 119, la compensación por hora hasta 100 y el salario horario hasta 72. Pero en el 


\section{Santiago Niño Becerra}

2009 mientras que la productividad había crecido en 80 puntos desde 1979, las compensaciones habían aumentado 8 y los salarios 7. ¿Cómo, entonces, los trabajadores USA pudieron consumir?, sencillo: endeudándose gracias a que se les concedió una creciente capacidad de endeudamiento: en 1947 la deuda de los hogares USA representaba el 26\% de sus ingresos, el $70 \%$ en 1979 , pero a partir de ahí, y tras un pequeño bache a principios de los 80 hasta que se acabó de perfilar el submodelo, la deuda va creciendo y se dispara a partir del 2000 hasta alcanzar el 132\% en el 2007. Salarios reales estancados, endeudamiento creciente, concentración del capital, productividad al alza, ... no es extraño que la concentración de la riqueza haya experimentado un viaje de ida y vuelta: mientras que en 1928 el 1\% más rico de la población ostentaba la posesión del $23,9 \%$ de la riqueza, las políticas fiscales y el pleno empleo con salarios crecientes de los años 50 y 60 disminuyeron esa cifra hasta el 8,9\% en 1976, para, con las políticas de la oferta, las posibilidades fiscales para los más ricos y las oportunidades para el capital de los 80,90 y 2000 han elevado la tasa de concentración hasta el 23,5\% en el $2007^{3}$. Esta desigualdad caracteriza una situación de rentas muy reducidas en las capas más bajas de la población y el progresivo retroceso de la clase media. Con mayor o menor énfasis, la situación es exportable a otras latitudes.

- Crisis política. La política en tándem con la ideología desempeñó un papel significativo entre principios del siglo XX y hasta finales de los años 70. Luego la importancia de la política fue retrocediendo hasta llegar, en Italia, entre el 16 de noviembre del 2011 y el 28 de abril del 2013, a que un Gobierno, integrado por técnicos, no fuese elegido por la ciudadanía en unas elecciones generales. Progresivamente, la creciente complejidad de las relaciones económicas internacionales y la interpenetración que en la ya postglobalización han alcanzado los vínculos entre áreas económicas, ha ido despolitizando crecientemente las tomas de decisiones en un retroceso continuado del rol de los políticos.

Debiendo asumir que absolutamente nada volverá a ser como fue ya que el pasado pertenece a un modelo agotado; que el escenario en el que se está produciendo el cambio se halla plagado de procesos que deben ser saneados y de excedentes que tienen que ser eliminados; y que las actuaciones deben producirse tanto a nivel global como específico.

Todo lo apuntado dibuja un posible punto de llegada:

- Equilibrio en desempleo, al menos al principio hasta que se vaya delimitando la cantidad de factores productivos precisos en cada momento.

${ }^{3}$ Fuente de los datos: Robert B. Reich, University of California, Berkeley, "The State of Working America" by the Economic Policy Institute, Thomas Piketty, Paris School of Economics, and Emmanuel Saez, University of California, Berkeley. The New York Times, September 4, 2011. 
- Subempleo del factor trabajo debido a un exceso de oferta de trabajo en contraste con una demanda decreciente.

- Elevado desempleo estructural como consecuencia de las dos situaciones anteriores.

- Fin de la clase media tal y como hasta ahora ha sido entendida: un grupo cohesionado de personas con empleo productivo y con una renta suficiente, que actuaba como tampón social.

- Crecimiento sesgado al ser la mayor parte generado por ciertas actividades y en ciertas áreas.

- En virtud de lo anterior, delimitación de clusters y zonas con posibilidades en las que se desarrollarán las actividades económicas generadoras de una mayor proporción de PIB.

- Desarrollo de la Industria 4.0 desvinculada de las instalaciones y maquinaria convencional orientada a la producción de grandes series masivas, es decir, una industria postmaquinización y aplicada a la customización.

- Progresiva evolución hacia la Sociedad 1/3: un tercio de excluidos, un tercio de personas parcial y muy parcialmente necesarias en los procesos productivos y de forma intermitente, y un tercio de personas mayormente necesarias.

Todo lo cual conformará un nuevo escenario característico de una nueva normalidad característica del nuevo modelo y diferente de la normalidad pasada y característica del modelo agotado.

\section{BIBLIOGRAFÍA}

BBVA, Research, noviembre 2014. Disponible en: https://www.bbvaresearch.com NIÑO BECERRA, S., El crash del 2010. Los Libros del Lince, Barcelona, marzo 2009.

Más allá del crash. Apuntes para una crisis. Los Libros del Lince, Barcelona, noviembre 2011.

Diario del Crash. Los Libros del Lince, Barcelona, noviembre 2013.

La Economía. Una Historia muy personal: Barcelona. Los Libros del Lince. febrero 2015.

REICH, R. B., University of California, Berkeley, "The State of Working America" by the Economic Policy Institute, Thomas Piketty, Paris School of Economics, and Emmanuel Saez, University of California, Berkeley. The New York Times, September 4, 2011. Disponible en: http://www.nytimes.com/imagepages/2011/09/04/opinion/04reich-graphic.html 
